\title{
Mitigating the seismic pounding of multi-story buildings in series using linear and nonlinear fluid viscous dampers
}

\author{
Hytham Elwardany ${ }^{1} \cdot$ Robert Jankowski ${ }^{2}$ [D $\cdot$ Ayman Seleemah $^{3}$
}

Received: 18 November 2020 / Revised: 6 May 2021 / Accepted: 15 May 2021 / Published online: 20 August 2021

(c) The Author(s) 2021

\begin{abstract}
Seismic-induced pounding between adjacent buildings may have serious consequences, ranging from minor damage up to total collapse. Therefore, researchers try to mitigate the pounding problem using different methods, such as coupling the adjacent buildings with stiff beams, connecting them using viscoelastic links, and installing damping devices in each building individually. In the current paper, the effect of using linear and nonlinear fluid viscous dampers to mitigate the mutual pounding between a series of structures is investigated. Nonlinear finite-element analysis of a series of adjacent steel buildings equipped with damping devices was conducted. Contact surfaces with both contactor and target were used to model the mutual pounding. The results indicate that the use of linear or nonlinear dampers leads to the significant reduction in the response of adjacent buildings in series. Moreover, the substantial improvement of the performance of buildings has been observed for almost all stories. From the design point of view, it is concluded that dampers implemented in adjacent buildings should be designed to resist maximum force of 6.20 or 1.90 times the design independent force in the case of using linear or nonlinear fluid viscous dampers, respectively. Also, designers should pay attention to the design of the structural elements surrounding dampers, because considerable forces due to pounding may occur in the dampers at the maximum displaced position of the structure.
\end{abstract}

Keywords Series of structures · Structural pounding · Linear fluid viscous dampers · Nonlinear fluid viscous dampers · Earthquakes · Contact surfaces

\section{Introduction}

Many cases of damage due to structural pounding between adjacent buildings have been observed under the influence of earthquakes. For example, collisions that occurred between parts of the school buildings during the Athens earthquake led to considerable damage and the collapse of the roof parapet [1]. It was also observed after the Mexico City earthquake that about $40 \%$ of the damaged buildings suffered some poundings, and in the case of $15 \%$ of them, collisions caused their collapse [2]. During the San Fernando

Robert Jankowski

jankowr@pg.edu.pl

1 Faculty of Engineering, Structural Engineering Department, Delta University for Science and Technology, Belkas, Egypt

2 Faculty of Civil and Environmental Engineering, Gdansk University of Technology, Gdansk, Poland

3 Faculty of Engineering, Structural Engineering Department, Tanta University, Tanta, Egypt earthquake, collisions between the Olive View Hospital and the independently standing stair towers caused damage to the towers resulting in their permanent inclination [3]. Over 200 evidences of collisions, involving more than 500 buildings, were detected after the Loma Prieta earthquake within the distance of $90 \mathrm{~km}$ from the epicenter [4]. Pounding may especially take place in the case of old RC existing structures where, as known, slippages of smooth reinforcing bars significantly decrease the lateral stiffness of the structures [5-10].

Lessons learned from previous earthquakes show that adjacent structures with small seismic gaps can suffer major damage or even complete collapse resulting from structural pounding [11]. Many efforts were devoted by the engineering community to overcome this problem. Research works were conducted either numerically or experimentally. In the case of numerical simulations of the pounding problem, researchers used different modeling approaches. For example, Jankowski [12] studied the efficiency of impact force response spectrum concept on the prediction of damage due 
to collisions between two adjacent structures modeled as single-degree-of-freedom systems and using nonlinear viscoelastic model of pounding force. The results indicated that the natural properties of structures influenced the behavior of colliding structures significantly. The effect of pounding between adjacent buildings with different base conditions was discussed in [13]. Anagnostopoulos and Spiliopoulos [14] studied the effect of mutual pounding on the response of multi-story buildings. The structures were modeled as multi-degree-of-freedom (MDOF) systems with the mass of each story lumped at the slab level. The study indicated that pounding could cause high overstresses for unequal-height buildings. The study focused on pounding between two adjacent 15 -story and 8 -story buildings was performed by Maison and Kasai [15]. The investigation concerned both formulation and solution of MDOF equations for the analyzed structures. The effect of earthquake-induced pounding on the seismic response and ductility requirements of reinforced concrete structures with unequal heights was studied in [16]. Columns were modeled by special elements with distributed plasticity. The study revealed that the ductility demand of the columns of the taller building increased significantly for the stories above the floor at which collisions occurred. Mahmoud and Jankowski [17] investigated the effect of pounding on elastic and inelastic responses of buildings. The results indicated that the nonlinear modeling of colliding structures is essential to obtain accurate seismic response. Moreover, Raheem [18] used the contact force-based method utilizing linear or nonlinear springs. Papadrakakis et al. [19] applied finite-element method to investigate the response of colliding buildings where single four-node plane stress elements were used to model the floors and four linear beamcolumn elements were used to model the walls.

While considerable research work to understand the seismic pounding phenomena was based on numerical simulations, only limited number of experimental studies was carried out on pounding between two or more structures. Chau et al. [20] experimentally studied the effect of both harmonic waves and earthquake excitation on the response of two adjacent steel towers. The study concluded that the stiffer structure was more susceptible to collisions, whereas pounding suppressed the response of the flexible structure. Jankowski et al. [21] conducted the shaking table experimental study on series of models of adjacent buildings under the effect of different earthquake excitations. The study confirmed that collisions affected rigid structures more than flexible ones. El-Khoriby et al. [22] conducted both experimental and numerical investigation focused on the seismic response on series of colliding buildings. The results revealed that a zero in-between gap size, as well as the distance large enough to prevent pounding, might be an appropriate selection. The effect of pounding between two-story steel frames with concrete slabs was experimentally investigated in [23]. The results showed the amplification and the unfamiliar shape of the response spectra of the impacting slabs which was also observed in previous studies.

Some research efforts were devoted to improve the structural behavior using seismic energy dissipation systems [24]. They mainly rely on specially designed devices which are able to dissipate large amount of energy [25]. There are many types of energy dissipation systems, including viscoelastic, electro-inductive, friction damping, and viscous dampers. Viscous dampers are particularly preferred, because they do not affect stiffness of buildings and thus do not affect their dynamic properties. Among their advantages, high ability to dissipate energy, relatively low maintenance requirements, possibility of installation in any building without affecting its geometry can also be mentioned [25].

Adding damping devices to mitigate pounding between adjacent buildings was widely investigated. For example, Kasai et al. [26] found that adding dampers to adjacent buildings had the ability to significantly reduce the effect of collisions. Moreover, Xu et al. [27] presented a formulation for MDOF equations of motion for adjacent multi-story structures connected with fluid dampers. The results showed that the appropriate selection of properties of dampers connecting different adjacent buildings was essential to suppress the structural response during earthquakes. Developed method for analyzing the seismic response of two adjacent buildings connected with nonlinear hysteretic dampers was presented by Ni et al. [28]. Coupling buildings with stiff beams was suggested in [29]. Bhaskararao and Jangid [30] investigated the effect of connecting two adjacent multistory symmetric plane structures with viscous, viscoelastic, and friction dampers so as to reduce the structural response. It was found that linking two adjacent structures by dampers improved the seismic behavior of the coupled system. Moreover, the appropriate locations of dampers may concern the places with the maximum relative displacement of adjacent floors. Uz and Hadi [31] studied the effect of connecting two multi-story adjacent buildings with fluid viscous dampers. The fluid viscous dampers were modeled using linear link elements in SAP 2000 software. The study concluded that dampers efficiently controlled the seismic response of the adjacent structures with different characteristics and height. Moreover, fluid viscous dampers were more successful in the shorter structures than in the taller ones. Investigation of coupling between two adjacent three-story buildings using link elements was carried out by Jankowski and Mahmoud [32]. Different types of links were considered in the analysis, including springs, dashpots, and viscoelastic elements installed at all stories. Various values of stiffness and damping were used for both springs and dashpots. The conclusions revealed that the response of the more flexible building was improved, whereas it did not change the stiffer building behavior. Moreover, using the viscoelastic element 
was found to be more effective than other elements in reducing the peak displacement of the lower structure.

Evaluation of the structural response during earthquakes may be carried out using the transfer function analysis. This type of analysis is very useful in studying the variation in the natural frequencies of buildings due to coupling. The detrimental effect may be observed on the seismic retrofitted structures due to changing its initial dynamic properties [33]. Gattulli et al. [34] reported failures observed in some portions of a building after 2009 L'Aquila earthquake. High stiffness of rigid links used to connect the facade and the frame was the reason for the observed damages. Connecting the structures changed their dynamic properties, forming a new stiffer system, substantially different comparing to the independent structural behavior. This new system attracted higher seismic forces, and the retrofitted buildings were not designed to withstand these forces.

According to the authors' knowledge, almost all studies focused on linking the adjacent buildings, so as to prevent their pounding during earthquakes, were conducted between two adjacent structures only. However, when the response of series of adjacent buildings is studied, it may be more realistic to implement dampers in each building rather than connecting series of adjacent buildings. This is due to the fact that different buildings might have different owners. Moreover, it might be difficult to adjust the dynamic properties of each building to be connected in series with other structures.

The present paper aims to study the effect of implementing both linear fluid viscous dampers (LFVD) and nonlinear fluid viscous dampers (NFVD) so as to mitigate seismic pounding between series of adjacent buildings. Three different adjacent structures with equal story height (slab-toslab pounding) were investigated (see Fig. 1). The analyzed buildings simulate actual existing cases. The single-bay multi-story structural systems, with modified masses and stiffness, such that they mimic the dynamic properties of the actual structures, were considered in the study, see [35]. The buildings were designed according to AISC [36]. The current study provides a clear picture on the effect of using LFVD and NFVD on the earthquake-induced pounding between adjacent structures in series. It also provides an assessment of the efficiency of designing dampers utilizing

Fig. 1 Buildings under study traditional ways in the case of pounding force affecting each structure.

\section{Finite-element analysis}

Each analyzed building is composed of four steel columns and four steel beams. The moment of inertia of each member is equal to $392.9 \mathrm{~cm}^{4}$. The beams carry a $15 \mathrm{~cm}$-thick concrete slab with $0.35 \mathrm{t} / \mathrm{m}^{2}$ weight for each story (see [35] for more details). The height of each story is $3.0 \mathrm{~m}$. The left and right buildings have three stories with total height of $9.0 \mathrm{~m}$, while the middle building has two stories with total height of $6.0 \mathrm{~m}$ (see Fig. 1). Seismic gap of $30 \mathrm{~mm}$ is specified between structures. The constant inherent damping of $2 \%$ of critical damping is considered for all modes of vibration. Three cases of investigation were conducted. The first case concerned the bare frame buildings without dampers. On the other hand, LFVD and NFVD were used in the second and the third case, respectively. The natural frequencies of the structures were obtained using the consistent mass matrix, see Table 1.

The nonlinear finite-element analysis software ADINA [37] was used in the study. Two-dimensional analysis was carried out using the direct integration method with time step of $0.005 \mathrm{~s}$. Moreover, the second order $\mathrm{P}-\Delta$ effect was also considered in the analysis. Three different ground motions were taken into consideration (see Table 2). No connectors between the adjacent buildings were used. Instead, the contact surface model with the contactor and target surface was considered in the analysis. These contact surfaces were identified as the areas at which collisions are expected to occur. These areas were divided into two parts, i.e., the contactor surface and the target one. Such an approach allows us to transfer the friction forces and pressure during impact (see [38, 39] for more details).

Table 1 Natural frequencies of adjacent bare frames (Hz)

\begin{tabular}{lll}
\hline Left building & Middle building & Right building \\
\hline 1.126 & 1.576 & 0.943 \\
\hline
\end{tabular}

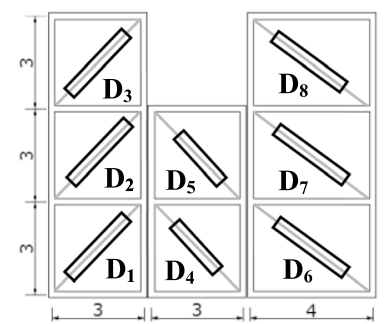

Case (2), LFVD

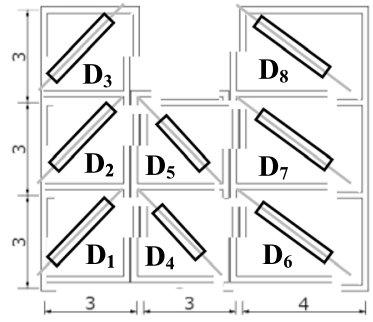

Case (3), NFVD 
Table 2 Ground motions used in the study

\begin{tabular}{lllll}
\hline Ground motion & Station & $\begin{array}{l}\text { Frequency range }^{\mathrm{a}} \\
(\mathrm{Hz})\end{array}$ & $\begin{array}{l}\text { Largest amplitude }_{\text {frequency }^{\mathrm{a}}} \\
(\mathrm{Hz})\end{array}$ & $\begin{array}{l}\text { Peak ground } \\
\text { acceleration }^{2} \\
\left(\mathrm{~m} / \mathrm{s}^{2}\right)\end{array}$ \\
\hline El Centro 1940, NS & Imperial Valley & $0.10-10.0$ & 1.17 & 3.070 \\
Taft 1952, S69E & Lincoln School & $0.10-8.0$ & 2.27 & 1.76 \\
Kocaeli 1999, EW & Izmit & $0.20-13.0$ & 3.30 & 2.26 \\
\hline
\end{tabular}

${ }^{\text {a}}$ Values obtained using FFT analysis

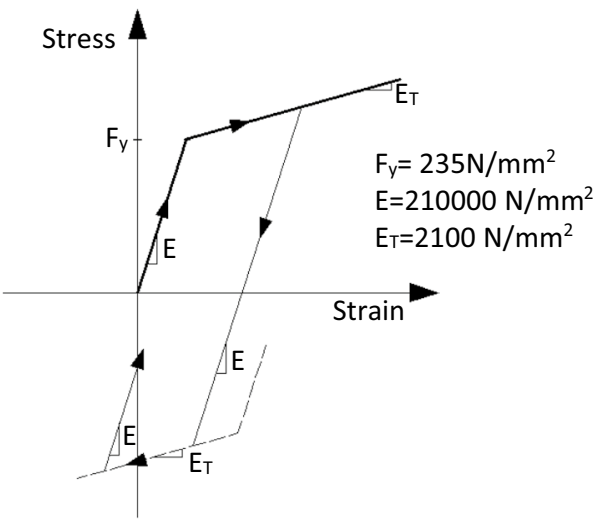

Fig. 2 Stress-strain relationship of steel (according to [41])

The material of the steel frames was considered to have the elastic-plastic behavior, as shown in Fig. 2, with yield stress $F_{\mathrm{y}}=235 \mathrm{MPa}$ (compare with [40]). Moreover, a $1 \%$ linear strain hardening and a Poisson's ratio of 0.30 were assumed according to [41].

\section{Viscous dampers}

Monteiro [25] described full details of the fluid viscous dampers consisting of a cylinder containing compressible silicone fluid. The process of dissipating energy during an earthquake occurs by transferring the force resulting from the imposed acceleration to the damper, which regulates the passage of the compressed silicon oil through small holes. Actually, this process depends on how fast the liquid passes through the holes. Both linear and nonlinear fluid viscous dampers were implemented in the analysis. Total damping ratios (inherent damping plus added damping using fluid viscous dampers) of 10,15 , and $20 \%$ for the dominant modes were considered. The force in the dampers were obtained according to the following equation [42]:

$F=\mathrm{CV}^{a}$,

where $C$ is the damping coefficient, $V$ is the velocity between the two ends of the damper, and $\alpha$ is the velocity exponent.
It should be added that stiffness of damper is disregarded in Eq. (1), since it is relatively low and does not affect stiffness of the whole building [42].

\subsection{Calculation of coefficients for fluid viscous dampers}

FEMA P-1051 [43] presents simple method to obtain the preliminary design and sizing of dampers:

1. The primary mode of vibration $T_{\mathrm{m}}$ should be determined using the modal analysis.

2. The targeted amount of the added damping for each primary mode should be selected.

3. Determine the pseudo-braced building primary periods $T_{\mathrm{ps}, \mathrm{m}}$, as shown in Eq. (2).

4. The area of the pseudo-braces that must be added to the mathematical model is calculated to obtain the same pseudo-braced period obtained from the previous step.

\subsubsection{LFVD coefficient}

The coefficient of LFVD was first calculated using the following equation [43]:

$T_{\mathrm{ps}, \mathrm{m}}=T_{\mathrm{m}} / \sqrt{ }\left(2 \xi_{\mathrm{m}}+1\right)$,

where $T_{\mathrm{ps}, \mathrm{m}}$ is the pseudo-braced building primary period of vibration, $T_{\mathrm{m}}$ is the natural structural vibration period, and $\xi_{\mathrm{m}}$ is the damping ratio. Moreover

$K_{\text {hor, } \mathrm{i}}=\frac{K_{\text {trial, } \mathrm{i}}}{\left[\frac{T_{\mathrm{m}}^{2}-T_{\text {trial }}^{2}}{T_{\mathrm{m}}^{2}-T_{\mathrm{ps}, \mathrm{m}}^{2}}\right]\left[\frac{T_{\mathrm{ps, \textrm {m }}}^{2}}{T_{\text {trial }}^{2}}\right]}$

$C_{\mathrm{L}, \mathrm{hor}, \mathrm{i}}=\frac{K_{\mathrm{hor}, \mathrm{i}} T_{\mathrm{m}}}{2 \pi}$,

where $T_{\text {trial }}$ is the trial period of structural vibration, $K_{\text {hor,i }}$ is the pseudo-horizontal stiffness at each story, and $C_{\mathrm{L}, \text { hor, }}$ is the horizontal LFVD constant for each story, i. For the diagonally oriented LFVD, the diagonal constant $C_{\mathrm{L}, \text { diag,i }}$ is estimated as 
$C_{\mathrm{L}, \text { diag, } \mathrm{i}}=\frac{C_{\mathrm{L}, \mathrm{hor}, \mathrm{i}}}{N_{\mathrm{i}} \cos ^{2} \theta}$

where $N_{\mathrm{i}}$ is the number of braced bays in the direction of interest and $\theta$ is the angle of inclination of the damper measured from the horizontal direction.

\subsubsection{NFVD coefficient}

The analysis was carried out utilizing NFVD with the velocity exponent $\alpha=0.50$. The coefficient of NFVD was calculated in this way that approximately a similar amount of energy per cycle as LFVD could be dissipated. The following equation was used (see [43] for more details):

$C_{\mathrm{NL}} \approx C_{\mathrm{L}} \frac{\sqrt{\pi}}{2}\left(\omega X_{0}\right)^{1-\alpha}$,

where $C_{\mathrm{L}}$ is the damping LFVD coefficient, $\omega$ is the fundamental frequency of the structure, and $X_{0}$ is the damper displacement corresponding to the required performance drift level.

\section{Results and discussion}

\subsection{Comparison between independent and pounding-involved cases for buildings with LFVD and NFVD}

Two comparisons were conducted during the investigation. The first one shows the effect of different damping ratios on the maximum damper forces under the El Centro earthquake. Whereas, the second one presents the effect of different earthquakes on the maximum damper forces with damping ratio of $\xi=15 \%$.

\subsection{Effect of different damping ratios on maximum damper forces}

To get an insight into the change in maximum damper forces due to pounding, all cases were solved for the case of independent vibrations (i.e., no pounding occurs) under the $\mathrm{El}$ Centro earthquake (see Table 2) and the results are listed in Tables 3 and 4 . Table 3 shows maximum forces in the LFVD dampers for both cases. The results indicate that pounding increased forces in the dampers up to $103 \%, 146 \%$, and $240 \%$ at the top of the left, middle, and right building with $\xi=10 \%$, respectively. Moreover, it reached $91.50,122.43$, and $219 \%$ at the top of the three buildings with $\xi=15 \%$. Furthermore, it reached $68,88.93$ and $186.14 \%$ at the top of the three buildings when $\xi=20 \%$. Table 3 shows that, in the case of NFVD, pounding increased forces in dampers 


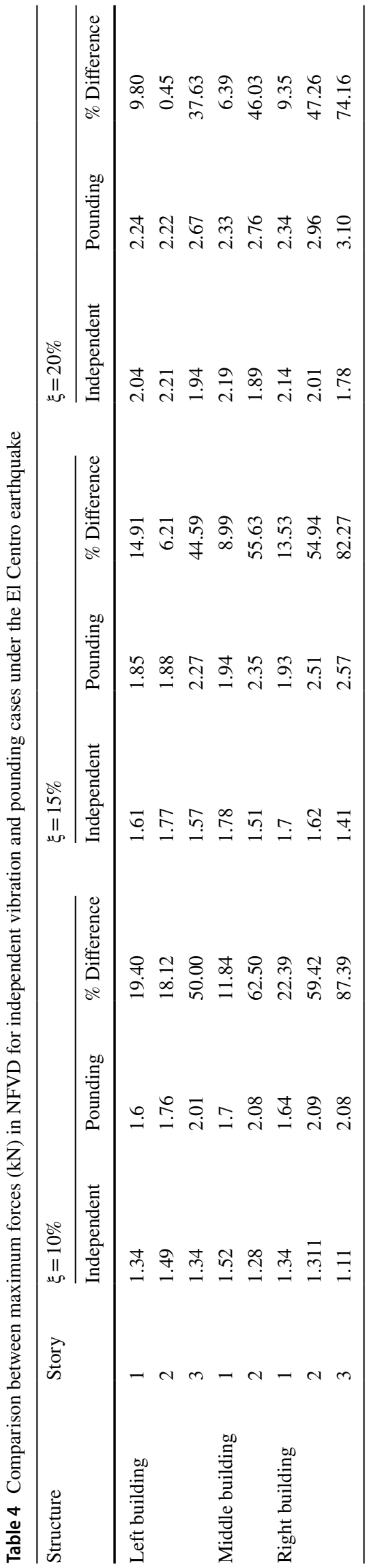

up to $50,62.50$, and $87.39 \%$ at the top of the left, middle, and right building with $\xi=10 \%$, respectively. Moreover, it reached $44.59,55.63$, and $82.27 \%$ for the left, middle, and right building with $\xi=15 \%$, respectively. Finally, it reached $37.63,46.03$, and $74.16 \%$ for the three successive buildings when $\xi=20 \%$.

Figure 3 shows a sample of loops of the damper force versus its axial displacement for the independent and poundinginvolved vibrations for different stories of the right building. The figure is plotted for the case of $\xi=10 \%$ for LFVD and NFVD cases. It can be observed for the figure that, generally speaking, the loops at the first floor for both cases look to be regular. This might be attributed to small pounding force caused by minor touch in the case of pounding-involved vibrations. For the second floor where a significant pounding occurred and the floor just above it (third floor), pounding significantly affected the behavior of dampers. Very irregular loops were observed especially for linear dampers. This observation is very important from the design point of view. This is due to the fact that, for the case without pounding, the forces in the dampers, and consequently the forces transmitted to the structural system, reach their minimum values at the maximum displacement. However, such situation does not take place in the case of pounding-involved vibrations. Instead, impact occurred at the time of maximum displacement and the force in the dampers reached significantly high values.

The results also show that the force in dampers of the right building was the most affected one due to pounding, as compared to the case of independent vibrations. For LFVD, pounding increased the maximum forces by $22.40,113.66$, and $240.16 \%$ for the first, second, and third floor with $\xi=10 \%$, respectively. Moreover, for NFVD with $\xi=10 \%$, the maximum force increased by $22.39,59.42$, and $87.39 \%$ for the first, second, and third floor, respectively.

Generally, the results indicate that increasing the damping ratio decreases the percentage of difference in maximum damper forces between the pounding-involved and the independent vibration cases for both LFVD and NFVD (see Tables 3, 4).

\subsection{Effect of different seismic excitations on the maximum damper forces}

The effect of different earthquakes on the maximum damper forces for both LFVD and NFVD with damping ratio of $\xi=15 \%$ was studied in more details. Table 5 shows the comparison between maximum forces in LFVD for independent vibration and pounding cases for the three different ground motions (see Table 2). The results show that the occurrence of collisions led to an increase in the maximum forces in dampers by about $219 \%$ for both the El Centro and Taft earthquakes and $518.60 \%$ for the Kocaeli earthquake, 

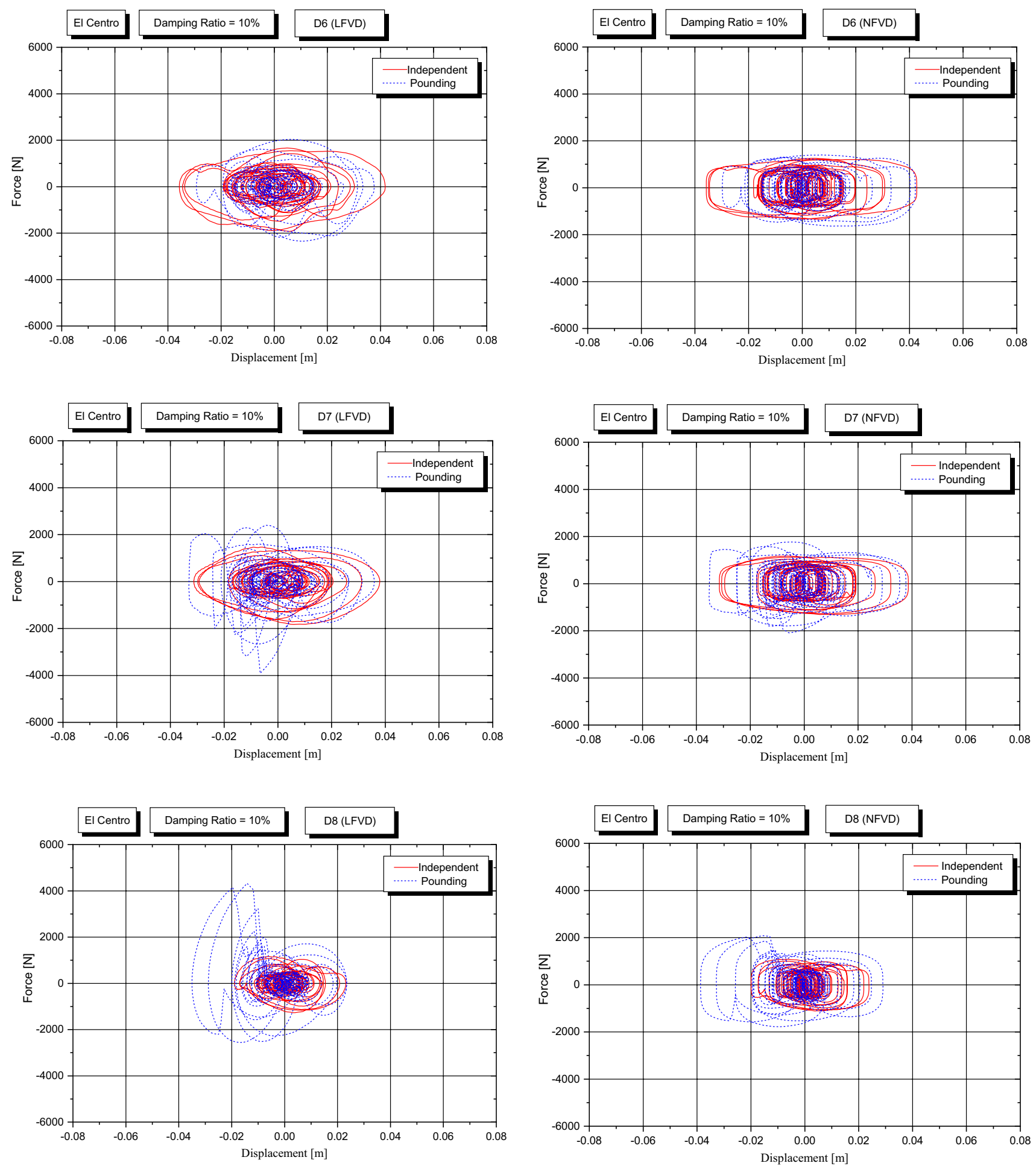

Fig. 3 Force-displacement behavior for independent and pounding-involved responses with LFVD and NFVD for the first (D6), second (D7), and third (D8) floor of the right building with $\xi=10 \%$

as compared to the independent vibration. This increase occurred on the third floor, which is the floor just above the collision level. Whereas, for NFVD, the increase in the maximum forces reached $82.27,51.89$, and $65.42 \%$ for the
El Centro, Taft, and Kocaeli earthquake, respectively, as compared to the independent vibration case (see Table 6).

Therefore, dampers for adjacent buildings, where pounding is expected to occur, should be designed to resist force 


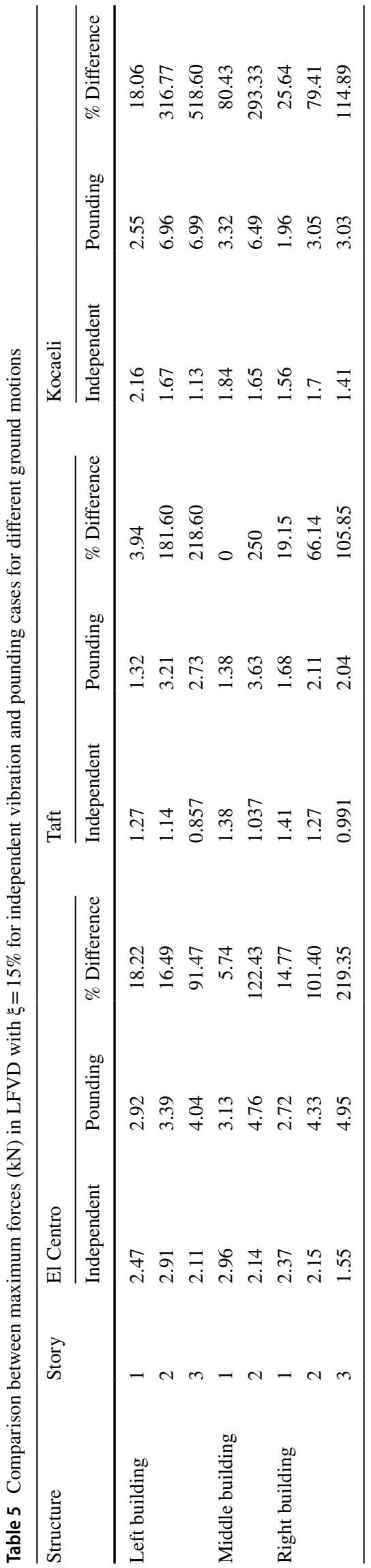

which is 1.20 -to-6.20 times the force assessed for independent structural vibrations in the case of LFVD, and 1.20-to1.90 times force assessed for independent structural vibrations in the case of NFVD. The exact value depends on the nature of the earthquake and the impact force. It is clear that using NFVD is preferable as the force output increments are smaller than those obtained when LFVD are applied. Hence, no special design consideration is required for the structures.

\subsection{Comparison between pounding-involved cases for LFVD, NFVD, and bare frame buildings}

Figure 4 shows the peak recorded accelerations for the three buildings when subjected to the El Centro earthquake. It is clear that using both LFVD and NFVD significantly decreases the accelerations of all floors. In particular, using the LFVD decreased the acceleration by $34.60 \%$ at the third floor of the right building with $\xi=10 \%$, and up to $97.93 \%$ at the first floor of the right building with $\xi=20 \%$. The same effect is observed with the NFVD as the acceleration was reduced by $31.5 \%$ at the third floor of the right building with $\xi=10 \%$, and up to $97.50 \%$ at the first floor of the right building with $\xi=20 \%$. This minor change in the percentage of reduction between the LFVD and NFVD is due to the fact that both of them were initially designed to dissipate the same amount of energy.

Figure 5 shows also that using the NFVD in the adjacent building significantly reduced the peak displacements, and the maximum reduction reached 37.78 and $48.32 \%$ at the second floor of the left and right structure with $\xi=10 \%$, respectively. On the other hand, the reduction reached $17.81 \%$ at the first floor of the middle building for the same damping ratio. Moreover, increasing the damping ratio to $15 \%$ decreased the peak displacement of the second floor of the left, middle, and right structure with maximum percentage of $39.65,18.46$, and $51.30 \%$, respectively. Moreover, increasing the damping ratio to $20 \%$ decreased the peak displacement at the second floor of the left, middle, and right building with maximum percentage of 43.76 , 28.43 , and $55.49 \%$, respectively. The results also show that using the LFVD in the adjacent buildings led to significant reduction in the peak displacements reaching its maximum at the second floor of the left, middle, and right building with $\xi=10 \%$ by $40.70,19.00$, and $50.90 \%$, respectively (see Fig. 5). Moreover, increasing the damping ratio to 15 and $20 \%$ decreased the peak displacement and reaching its maximum at the second floor of the left, middle, and right structure with $\xi=15 \%$ by $43.00,28.00$ and $53.91 \%$ respectively. Also, the reduction of 39.30 and $58.64 \%$ was observed for the middle and right building with $\xi=20 \%$. On the other hand, the reduction reached $49.75 \%$ at the first floor of the left structure with $\xi=20 \%$. Generally speaking, it is 
Table 6 Comparison between maximum forces $(\mathrm{kN})$ in NFVD with $\xi=15 \%$ for independent vibration and pounding cases for different ground motions

\begin{tabular}{|c|c|c|c|c|c|c|c|c|c|c|}
\hline \multirow[t]{2}{*}{ Structure } & \multirow[t]{2}{*}{ Story } & \multicolumn{3}{|l|}{ El Centro } & \multicolumn{3}{|l|}{ Taft } & \multicolumn{3}{|l|}{ Kocaeli } \\
\hline & & Independent & Pounding & $\%$ Difference & Independent & Pounding & $\%$ Difference & Independent & Pounding & $\%$ Difference \\
\hline \multirow[t]{3}{*}{ Left building } & 1 & 1.61 & 1.85 & 14.91 & 1.10 & 1.29 & 17.27 & 1.47 & 1.59 & 8.16 \\
\hline & 2 & 1.77 & 1.88 & 6.21 & 1.06 & 1.61 & 51.89 & 1.29 & 1.45 & 12.4 \\
\hline & 3 & 1.57 & 2.27 & 44.59 & 0.921 & 1.33 & 44.41 & 1.07 & 1.77 & 65.42 \\
\hline \multirow[t]{2}{*}{ Middle building } & 1 & 1.78 & 1.94 & 8.99 & 1.15 & 1.15 & 0 & 1.37 & 1.37 & 0 \\
\hline & 2 & 1.51 & 2.35 & 55.63 & 1.00 & 1.16 & 16 & 1.30 & 1.69 & 30 \\
\hline \multirow[t]{3}{*}{ Right building } & 1 & 1.7 & 1.93 & 13.53 & 1.29 & 1.41 & 9.30 & 1.36 & 1.55 & 13.97 \\
\hline & 2 & 1.62 & 2.51 & 54.94 & 1.24 & 1.43 & 15.32 & 1.43 & 1.44 & 0.7 \\
\hline & 3 & 1.41 & 2.57 & 82.27 & 1.10 & 1.41 & 28.18 & 1.33 & 1.88 & 41.35 \\
\hline
\end{tabular}
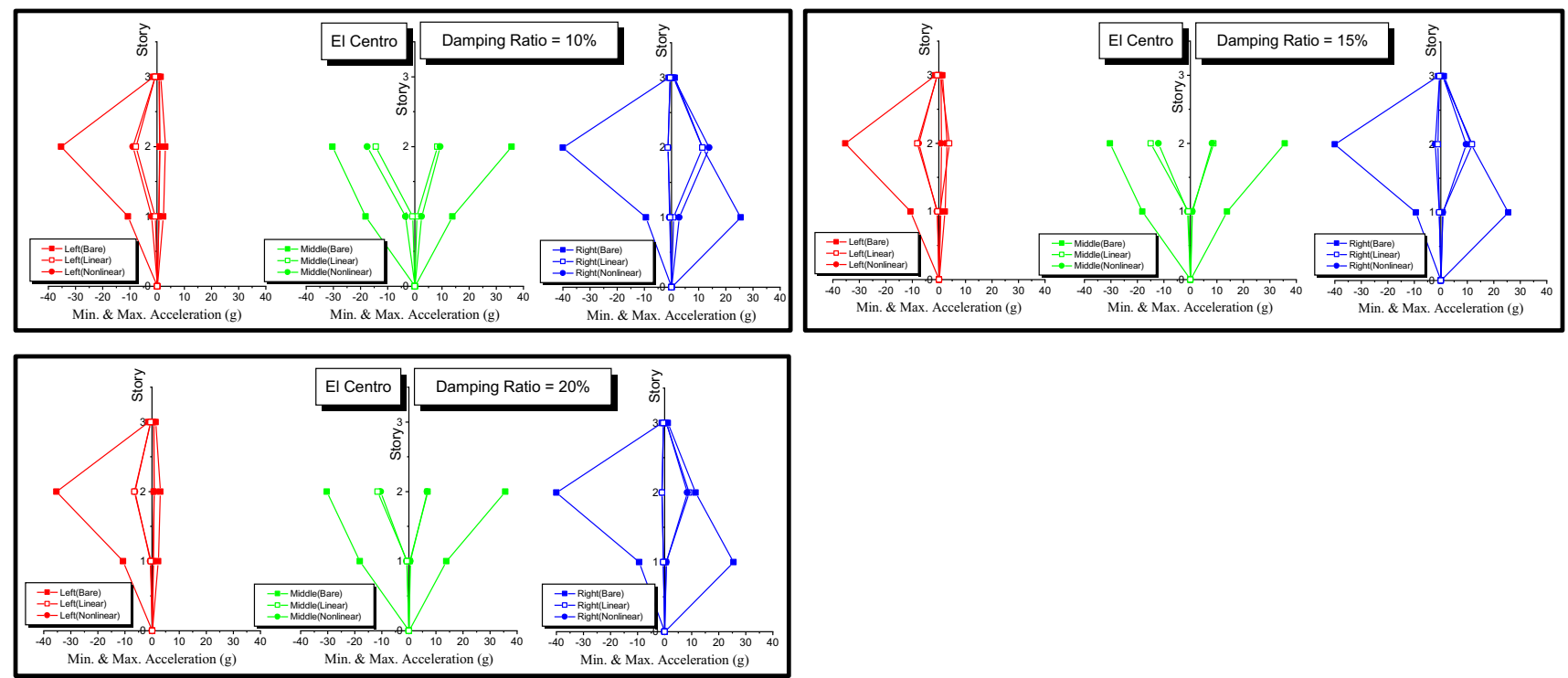

Fig. 4 Peak acceleration for bare frame buildings as well as for LFVD and NFVD

observed that using linear or nonlinear dampers leads to the significant decrease in the peak displacements of all three buildings (see Table 7).

It should also be underlined that using dampers in the buildings significantly changed the pattern of pounding. For example, the left building without dampers suffered five impacts at the first floor and about fifteen at the second floor (see Fig. 6). For LFVD with $\xi=10 \%$, no pounding was observed at the first floor, while only four collisions took place at the second floor and they occurred at the end of the earthquake (see Fig. 6). Moreover, the maximum pounding force was reduced by $45.20 \%$ in the case of structures with $\xi=10 \%$, as compared to buildings without dampers (see Table 7). On the other hand, for NFVD installed at buildings with $\xi=10 \%$, only one impact of $32.58 \mathrm{kN}$ was observed at the first floor with reduction of $38.67 \%$, as compared to buildings without dampers. Also, four collisions were observed at the second floor within the first $5 \mathrm{~s}$ of the earthquake and the maximum pounding force decreased by $30.40 \%$, as compared to the bare frame case (see Fig. 6; Table 7). It is also observed that increasing the damping ratio to $15 \%$ decreased the impact force at the second floor by 56.08 and $48.78 \%$ for LFVD and NFVD, respectively. Moreover, increasing the damping ratio to $20 \%$ decreased the impact force at the second floor by $59.20 \%$ for LFVD, while no significant change was observed for the case of NFVD installed at the structures with $\xi=15 \%$. Moreover, no pounding was also observed at the first floor for both linear and nonlinear dampers with $\xi=15$ and $20 \%$ (see Fig. 6; Table 7).

Regarding the right building, it is noticed that, in the case of buildings without dampers, eight collisions were observed at the first floor up to 20th second of the earthquake. Moreover, 11 impacts occurred at the second floor 

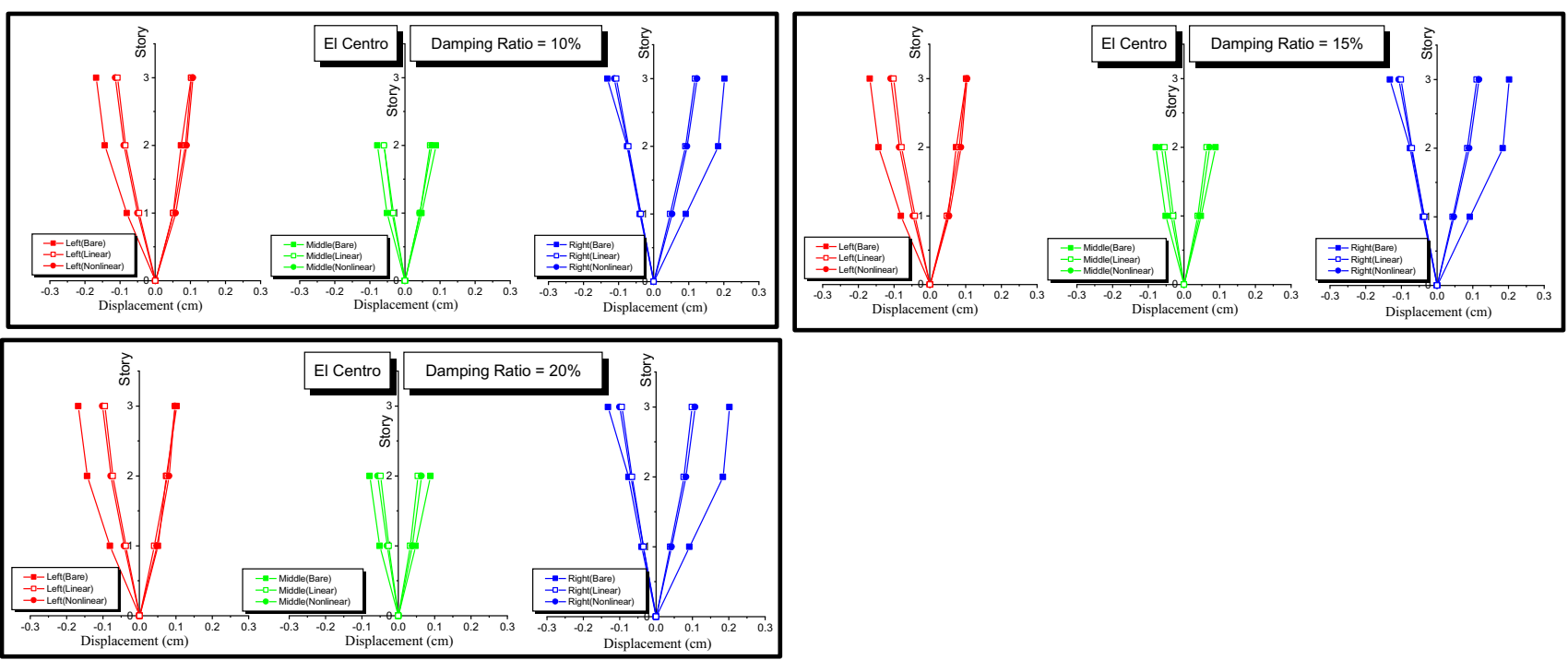

Fig. 5 Peak displacement for bare frame buildings as well as for LFVD and NFVD

Table 7 Ratio of displacements, accelerations and pounding forces for cases under study with LFVD and NFVD as compared to bare frames

\begin{tabular}{|c|c|c|c|c|c|c|c|c|}
\hline & \multirow[t]{3}{*}{ Structure } & \multirow[t]{3}{*}{ Story } & \multicolumn{6}{|c|}{$\%$ Difference } \\
\hline & & & \multicolumn{2}{|l|}{$\xi=10 \%$} & \multicolumn{2}{|l|}{$\xi=15 \%$} & \multicolumn{2}{|l|}{$\xi=20 \%$} \\
\hline & & & LFVD & NFVD & LFVD & NFVD & LFVD & NFVD \\
\hline \multirow[t]{8}{*}{ Acceleration } & \multirow[t]{3}{*}{ Left building } & 1 & -93.49 & -81.14 & -94.72 & -92.86 & -95.77 & -94.0 \\
\hline & & 2 & -77.94 & -74.78 & -76.78 & -78.28 & -81.41 & -81.93 \\
\hline & & 3 & -48.0 & -40.31 & -54.19 & -47.59 & -58.43 & -53.23 \\
\hline & \multirow[t]{2}{*}{ Middle building } & 1 & -95.14 & -81.20 & -95.64 & -93.80 & -96.26 & -95.33 \\
\hline & & 2 & -59.61 & -50.76 & -58.06 & -66.24 & -67.57 & -70.62 \\
\hline & \multirow[t]{3}{*}{ Right building } & 1 & -97.17 & -88.87 & -97.29 & -97.09 & -97.93 & -97.50 \\
\hline & & 2 & -72.13 & -66 & -71.25 & -76.59 & -77.79 & -79.48 \\
\hline & & 3 & -34.60 & -31.50 & -39.83 & -34.50 & -47.90 & -40.99 \\
\hline \multirow[t]{8}{*}{ Displacement } & \multirow[t]{3}{*}{ Left building } & 1 & -35.89 & -28.59 & -41.34 & -33.66 & -49.75 & -41.21 \\
\hline & & 2 & -40.70 & -37.78 & -43.00 & -39.65 & -47.29 & -43.76 \\
\hline & & 3 & -36.31 & -32.50 & -39.46 & -35.12 & -42.0 & -39.46 \\
\hline & \multirow[t]{2}{*}{ Middle building } & 1 & -16.83 & -17.81 & -24.95 & -16.05 & -35.62 & -24.66 \\
\hline & & 2 & -19.00 & -13.70 & -28.00 & -18.46 & -39.30 & -28.43 \\
\hline & \multirow[t]{3}{*}{ Right building } & 1 & -48.69 & -42.47 & -52.18 & -48.69 & -57.31 & -53.65 \\
\hline & & 2 & -50.90 & -48.32 & -53.91 & -51.30 & -58.64 & -55.49 \\
\hline & & 3 & -41.64 & -38.80 & -45.15 & -42.14 & -51.04 & -47.13 \\
\hline \multirow[t]{4}{*}{ Pounding forces } & \multirow[t]{2}{*}{ Left building } & 1 & $-100 *$ & -38.67 & $-100 *$ & $-100 *$ & $-100^{*}$ & $-100 *$ \\
\hline & & 2 & -45.20 & -30.40 & -56.08 & -48.78 & -59.20 & -47.99 \\
\hline & \multirow[t]{2}{*}{ Right building } & 1 & $-100 *$ & -95.20 & $-100^{*}$ & -98.0 & $-100 *$ & $-100 *$ \\
\hline & & 2 & -6.00 & +24.17 & $5.60+$ & -4.90 & +10.80 & +4.22 \\
\hline
\end{tabular}

+Increase in the percentage as compared to bare frames; - reduction in the percentage as compared to bare frames; * fluid viscous dampers prevented pounding (no pounding occurred) up to the 16th second of the earthquake (see Fig. 6). Significant change in the behavior of the right building was observed after adding dampers to the building. For LFVD with $\xi=10 \%$, no pounding was observed at the first floor and only five collisions took place at the second floor up to almost the end of the earthquake, and the pounding force slightly decreased by $6 \%$. Moreover, no pounding was observed at the first floor for both $\xi=15$ and $20 \%$. On the other hand, minor increase in the pounding force, 

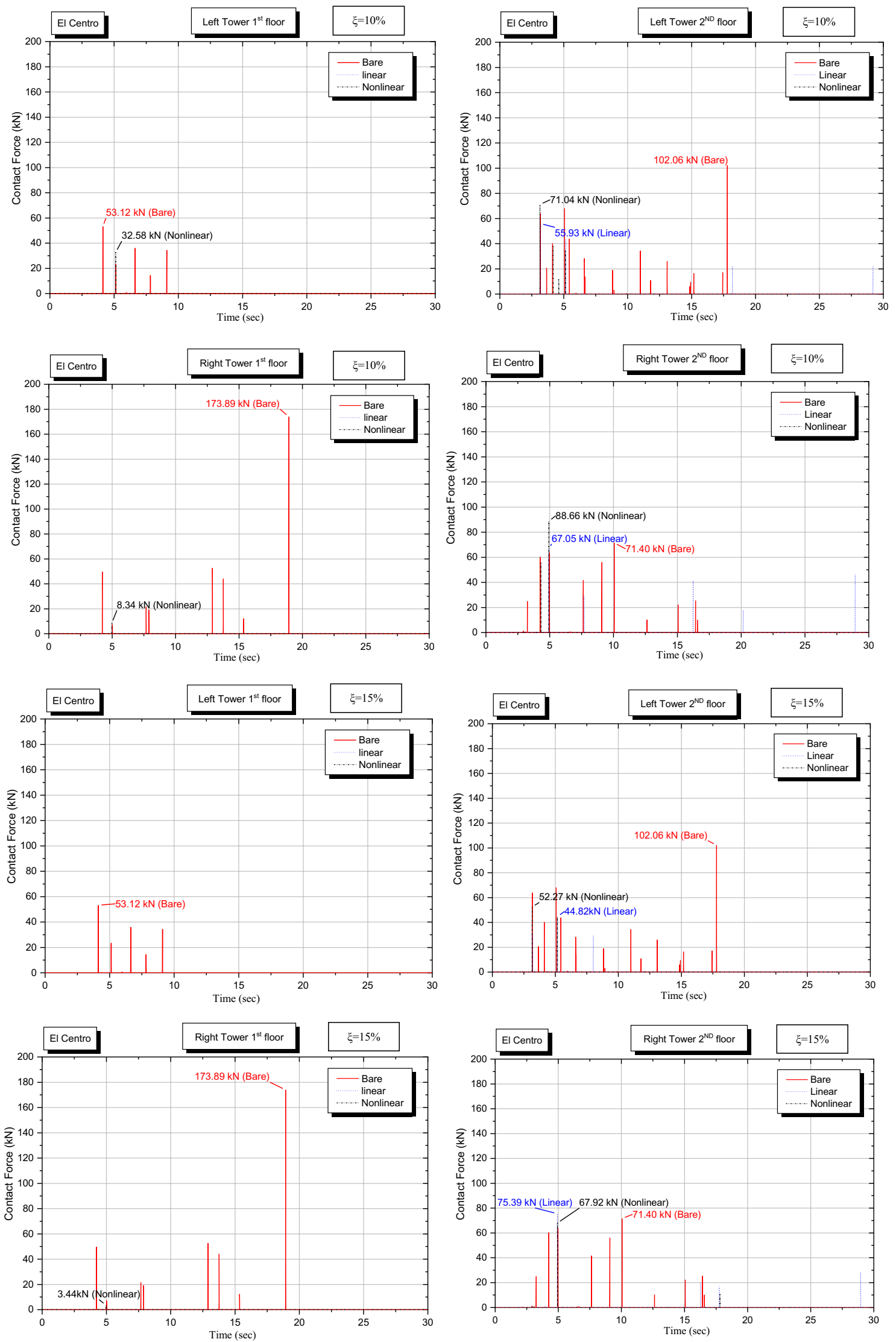

Fig. 6 Pounding force at the first and second floor for bare, LFVD, and NFVD with different damping ratios 

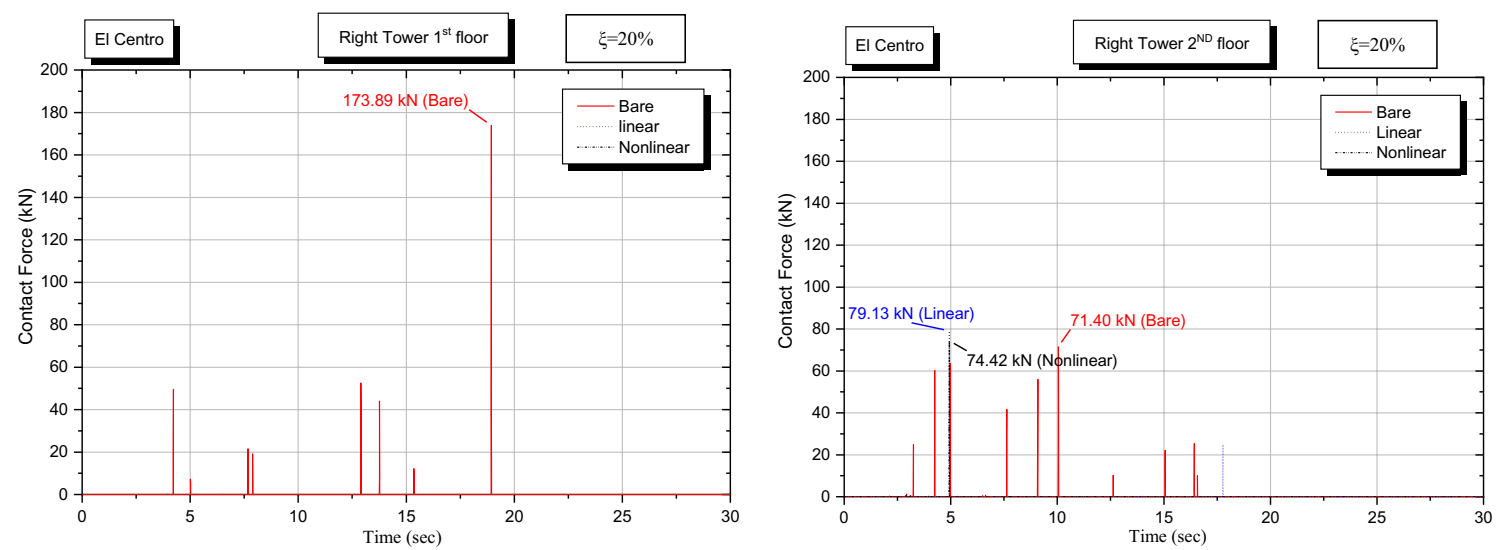

Fig. 6 (continued)

i.e., by $5.60 \%$ and $10.8 \%$, occurred at the second floor for $\xi=15$ and $20 \%$, respectively.

For NFVD with damping ratio $\xi=10 \%$, only light touch with $8.34 \mathrm{kN}$ at the first floor of the right building was observed with reduction of the pounding force by $95.20 \%$, as compared to the bare frame case. Also, a moderate increase (equal to $24.17 \%$ ) in the pounding force took place at the second story of the right building. This is because, at the moment of contact, the right structure was moving out of phase directly towards the middle building which acted as a stopper for the right structure causing an increase in the acceleration by $23 \%$, as compared to the linear damper. Increasing the damping ratio to $15 \%$, slightly decreased the pounding force by $4.90 \%$, as compared to the bare frames. On the other hand, only light touch of $3.44 \mathrm{kN}$ was observed at the first floor with $\xi=15 \%$. Moreover, slight increase in the pounding force by only $4.22 \%$ occurred at the second floor with $\xi=20 \%$. On the other hand, no pounding was observed at the first floor with $\xi=20 \%$.

Table 8 shows the ductility demand ratios, the interstory drift and the maximum story shearing force of the buildings studied. The results show that, for buildings without dampers, the ductility demand resulting in all stories exceeded the available ductility by $3-134 \%$. These two extreme values occurred at the first floor of the middle building and third floor of the left building, respectively.

It is also observed that pounding increased the interstory drift for all buildings, so that it exceeded the allowable limits of the UBC 1997 standard for almost all cases. The only exception concerned the first floor of the middle structure where the interstory drift ratio reached $1.70 \%$ and it did not exceed the allowable limit. Moreover, for buildings without dampers, the story shearing forces reached the yield strength in all stories.

On the other hand, buildings equipped with LFVD behaved elastically for almost all cases. Plastic behavior was observed only at the first floor of the left building where $\mu$ reached value of 0.92 and 0.84 for $\xi=10 \%$ and $\xi=15 \%$, respectively. For the case of $\xi=20 \%$, no plastic behavior was observed in all stories. It can also be observed that increasing the damping ratio decreased the interstory drift ratio for all cases.

Moreover, buildings equipped with NFVD behaved elastically for almost all stories except for the specific locations, i.e., the first floor of the left building with $\xi=10,15$, and $20 \%$, as well as the first floor of the right structure with $\xi=10 \%$. For these plastic cases, the ductility demand was smaller than the available value, except for the left building with $\xi=10 \%$ where minor increase by only $2 \%$ at the first floor was observed. Even for these plastic cases, the increase in the damping ratio decreased $\mu$ by $28 \%, 33 \%$, and $41 \%$ for $\xi=10 \%, 15 \%$, and $20 \%$, respectively, as compared to bare frame buildings. Moreover, for all cases, the interstory drift was lower than the UBC 1997 allowable limits of 0.025 and 0.02 times the story height for buildings having natural time period less/equal or greater than $0.70 \mathrm{~s}$, respectively. It was also observed that, for almost all cases, the increase in the damping ratio decreased the ductility demand, the interstory drift and the story shear.

Figure 7 shows the displacement time histories for the first floor of the left building with $\xi=2,10,15$, and $20 \%$ as well as for the first floor of the right building with $\xi=2 \%$ and $10 \%$. It can be clearly seen from the figure that pounding affected the response of the bare frame buildings with $\xi=2 \%$ as it behaved plastically with permanent displacement. On the other hand, using either LFVD or NFVD maintained the elastic behavior for almost all floors of the three buildings, except for the first floor of the left structure with $\xi=10,15$, and $20 \%$ as well as, for the first floor of the right building with $\xi=10 \%$. Moreover, pounding increased the interstory drifts as well as the peak story shear beyond the yield strength for these four cases. Moreover, using linear or nonlinear dampers decreased the ductility demand and 


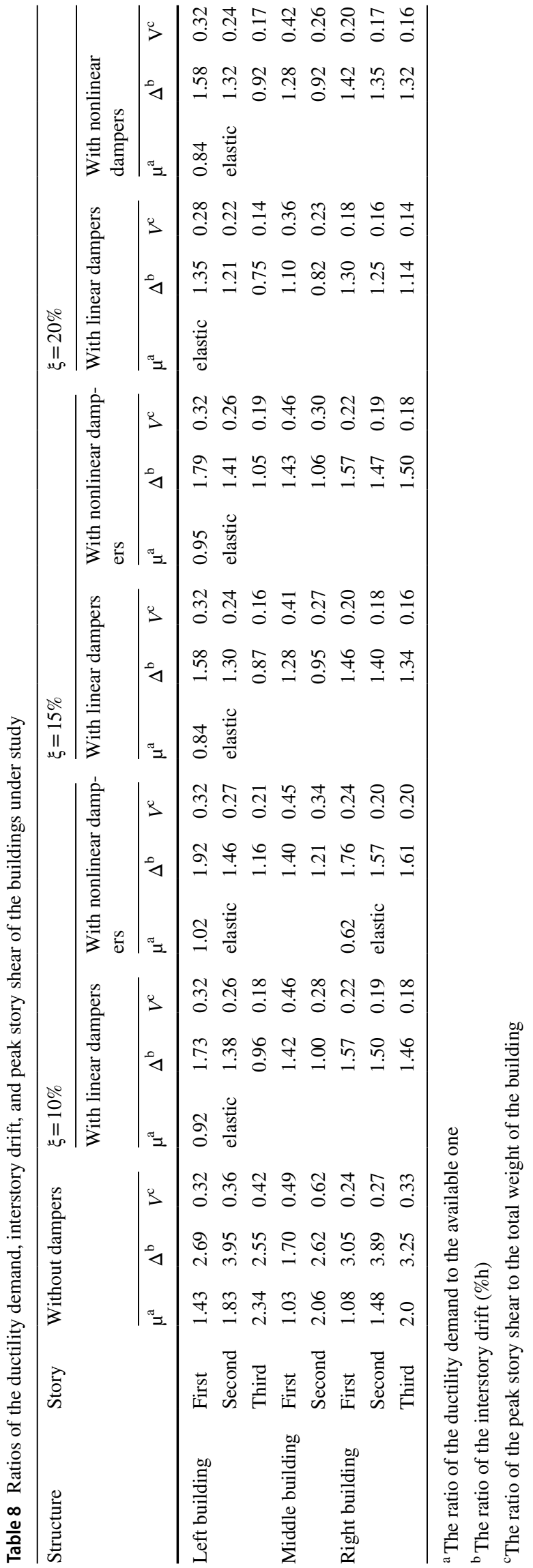

the interstory drift for the four cases, as previously shown in Table 8.

Table 9 presents the maximum damper forces for all studied cases. It is clear that while linear and nonlinear dampers were initially designed to dissipate the same amount of energy, the maximum forces in the NFVD are smaller than those in the LFVD by 29-52\%. Accordingly, using NFVD is preferable as no special design consideration is required for the structures.

\section{Conclusions}

In the current paper, the effectiveness of using both LFVD and NFVD in mitigation of the mutual earthquake-induced pounding between series of adjacent buildings has been investigated. Both types of dampers were initially designed to dissipate the same amount of energy. Nonlinear finiteelement analyses were conducted using numerical models of three buildings with different dynamic properties. The following conclusions were obtained:

1. Using LFVD or NFVD significantly reduced the structural response of series of adjacent buildings exposed to earthquake-induced pounding. Also, they significantly changed the pattern of pounding with smaller number of impacts, as compared to the bare frame case. Moreover, significant decrease in the maximum pounding force was observed for almost all cases.

2. For bare frame buildings, pounding increased the interstory drift, so that it exceeded the allowable limits of the UBC 1997 standard for almost all cases. Moreover, the story shearing force reached the yield strength for all stories. Also, the ductility demand for all stories exceeded the available value by $3-134 \%$. On the other hand, using LFVD or NFVD significantly improved the performance of adjacent buildings as the elastic structural behavior was observed for almost all stories.

3. Based on the results obtained in this study, dampers installed in adjacent buildings prone to pounding should be designed to resist the force of 1.20-to-6.20 times larger than the design independent force for linear dampers, and 1.20-to-1.90 times larger than the design independent force for nonlinear dampers. The exact value depends on the nature of the earthquake and the impact force. It is clear that using NFVD is preferable as the force output increments are smaller than those obtained when LFVD are applied. Hence, no special design consideration is required for the structures.

4. Pounding affected the shape of the dampers' force-displacement loops at the second floor where collisions occurred, and at the floor just above the level of collisions (third floor). This is different from the no-pound- 

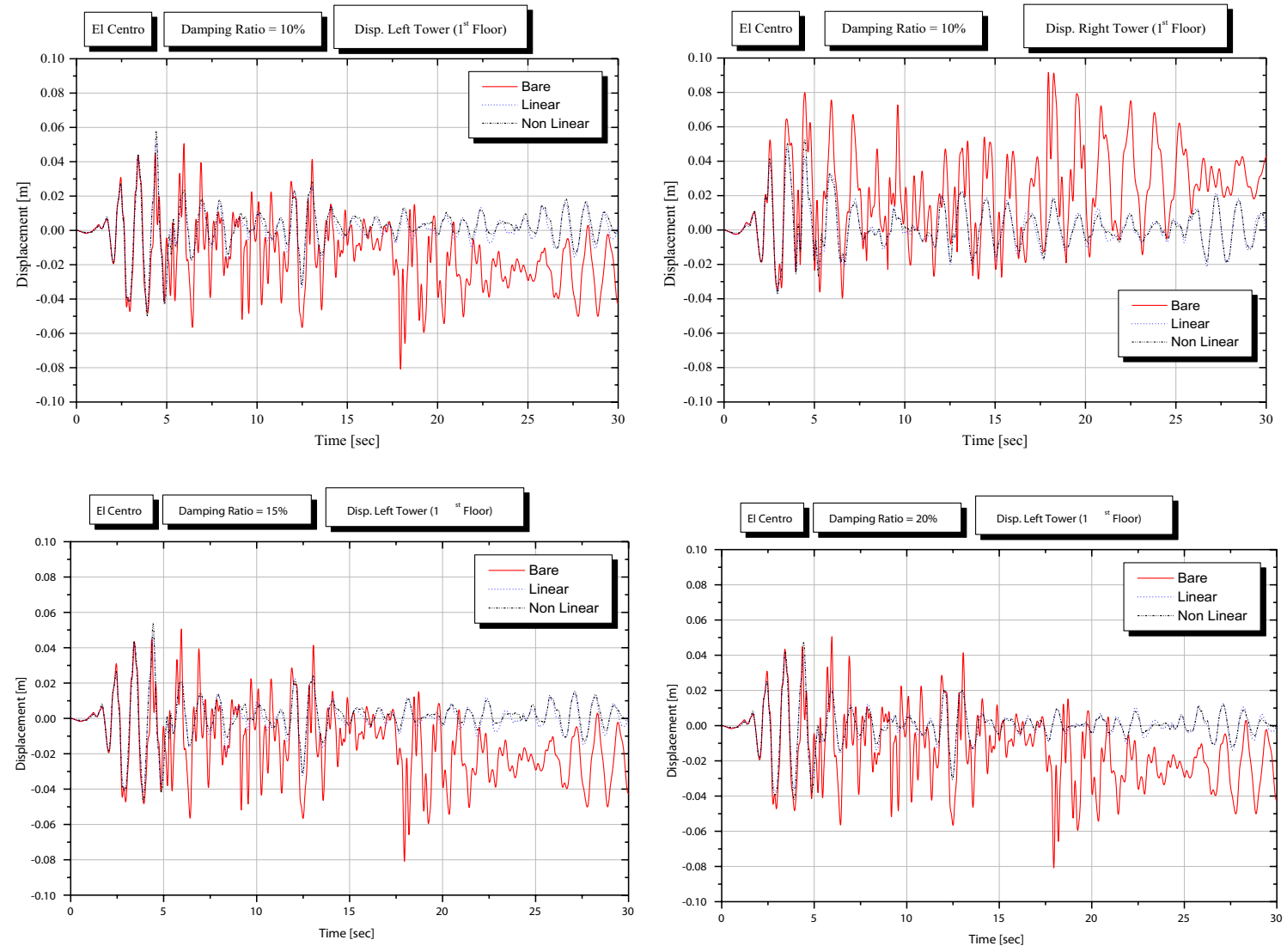

Fig. 7 Displacement time histories for the first floor of the left building with $\xi=10,15$, and $20 \%$ and the first floor of the right building with $\xi=10 \%$

Table 9 Comparison between maximum forces $(\mathrm{kN})$ in LFVD and NFVD for pounding cases

\begin{tabular}{|c|c|c|c|c|c|c|c|c|c|c|}
\hline \multirow[t]{2}{*}{ Structure } & \multirow[t]{2}{*}{ Story } & \multicolumn{3}{|c|}{$\xi=10 \%$-pounding } & \multicolumn{3}{|c|}{$\xi=15 \%$-pounding } & \multicolumn{3}{|c|}{$\xi=20 \%$ - pounding } \\
\hline & & LFVD & NFVD & $\%$ Difference & LFVD & NFVD & $\%$ Difference & LFVD & NFVD & $\%$ Difference \\
\hline \multirow[t]{3}{*}{ Left building } & 1 & 2.45 & 1.6 & -34.69 & 2.92 & 1.85 & -36.64 & 3.34 & 2.24 & -32.93 \\
\hline & 2 & 2.88 & 1.76 & -38.89 & 3.39 & 1.88 & -44.54 & 4.03 & 2.22 & -44.91 \\
\hline & 3 & 3.65 & 2.01 & -44.93 & 4.04 & 2.27 & -43.81 & 4.29 & 2.67 & -37.76 \\
\hline \multirow[t]{2}{*}{ Middle building } & 1 & 2.71 & 1.7 & -37.27 & 3.13 & 1.94 & -38.02 & 3.8 & 2.33 & -38.68 \\
\hline & 2 & 4.33 & 2.08 & -51.96 & 4.76 & 2.35 & -50.63 & 5.12 & 2.76 & -46.09 \\
\hline \multirow[t]{3}{*}{ Right building } & 1 & 2.35 & 1.64 & -30.21 & 2.72 & 1.93 & -29.04 & 3.61 & 2.34 & -35.18 \\
\hline & 2 & 3.91 & 2.09 & -46.55 & 4.33 & 2.51 & -42.03 & 4.89 & 2.96 & -39.47 \\
\hline & 3 & 4.32 & 2.08 & -51.85 & 4.95 & 2.57 & -48.08 & 5.78 & 3.1 & -46.37 \\
\hline
\end{tabular}

ing cases where the force approaches its minimum value at the maximum structural displacement. Accordingly, designers should pay special attention to the irregularity of the damper forces at maximum displacement due to pounding and its effect on surrounding structural elements.

5. Generally, the results indicate that increasing the damping ratio $(10,15$, and $20 \%)$ decreases the percentage of the difference in maximum damper forces between the pounding-involved and the independent vibration cases for both LFVD and NFVD.

Funding No funding was obtained.

Availability of data and materials Paper contains all data used in the study. 


\section{Declarations}

Conflict of interest The authors declare no conflict of interest.

Open Access This article is licensed under a Creative Commons Attribution 4.0 International License, which permits use, sharing, adaptation, distribution and reproduction in any medium or format, as long as you give appropriate credit to the original author(s) and the source, provide a link to the Creative Commons licence, and indicate if changes were made. The images or other third party material in this article are included in the article's Creative Commons licence, unless indicated otherwise in a credit line to the material. If material is not included in the article's Creative Commons licence and your intended use is not permitted by statutory regulation or exceeds the permitted use, you will need to obtain permission directly from the copyright holder. To view a copy of this licence, visit http://creativecommons.org/licenses/by/4.0/.

\section{References}

1. Vasiliadis L, Elenas A. Performance of school buildings during the Athens earthquake of 7 September 1999. In: 12th European conference on earthquake engineering. 2002, paper ref. 264

2. Rosenblueth E, Meli R. The 1985 earthquake: causes and effects in Mexico City. Concr Int. 1986;8:23-34.

3. Bertero VV, Collins RG. Investigation of the failures of the Olive View stair towers during the San Fernando earthquake and their implications on seismic design. EERC report No. 73-26. Berkeley: Earthquake Engineering Research Center, University of California; 1973.

4. Kasai K, Maison BF. Building pounding damage during the 1989 Loma Prieta earthquake. Eng Struct. 1997;19:195-207.

5. Laterza M, et al. Modeling of gravity-designed RC sub-assemblages subjected to lateral loads. Eng Struct. 2017;130:242-60.

6. Melo J, et al. Cyclic response of RC beam-column joints reinforced with plain bars: an experimental testing campaign. The 15th World Conference on Earthquake Engineering (15 WCEE), 24-28 September 2012

7. Braga $\mathrm{F}$, et al. Hardening slip model for reinforcing steel bars. Earthq Struct. 2015;9(3):503-39.

8. Fernandes $\mathrm{C}$, et al. Cyclic behavior of substandard reinforced concrete beam-column joints with plain bars. ACI Struct J. 2013;110(1):137-48.

9. Di Lorenzo G, et al. State-of-the-art on steel exoskeletons for seismic retrofit of existing RC buildings. Ingegneria Sismica. 2020;37(1):33-50.

10. D'Amato M, et al. Validation of a modified steel bar model incorporating bond-slip for seismic assessment of concrete structures. J Struct Eng ASCE. 2012;138(11):1351-60.

11. Anagnostopoulos SA. Pounding of buildings in series during earthquakes. Earthq Eng Struct Dyn. 1988;16:443-56.

12. Jankowski R. Impact force spectrum for damage assessment of earthquake-induced structural pounding. Key Eng Mater. 2005;293-294:711-8

13. Miari M, Choong KK, Jankowski R. Seismic pounding between adjacent buildings: identification of parameters, soil interaction issues and mitigation measures. Soil Dyn Earthq Eng. 2019;121:135-50.

14. Anagnostopoulos SA, Spiliopoulos KV. An investigation of earthquake induced pounding between adjacent buildings. Earthq Eng Struct Dyn. 1992;21:289-302.

15. Maison BF, Kasai K. Dynamics of pounding when two buildings collide. Earthq Eng Struct Dyn. 1992;21(9):771-86.
16. Karayannis CG, Favvata MJ. Earthquake-induced interaction between adjacent reinforced concrete structures with non-equal heights. Earthq Eng Struct Dyn. 2005;34(1):1-20.

17. Mahmoud S, Jankowski R. Elastic and inelastic multi-storey buildings under earthquake excitation with the effect of pounding. J Appl Sci. 2009;9(18):3250-62.

18. Raheem SEA. Seismic pounding between adjacent building structures. Electron J Struct Eng. 2006;6:66-74.

19. Papadrakakis M, Apostolopoulou C, Zacharopoulos A, Bitzarakis S. Three-dimensional simulation of structural pounding during earthquakes. J Eng Mech. 1996;122:423-31.

20. Chau KT, Wei XX, Guo X, Shen CY. Experimental and theoretical simulations of seismic poundings between two adjacent structures. Earthq Eng Struct Dyn. 2003;32:537-54.

21. Jankowski R, Seleemah A, El-Khoriby S, Elwardany H. Experimental study on pounding between structures during damaging earthquakes. Key Eng Mater. 2015;627:249-52.

22. El-Khoriby S., Seleemah A., Elwardany H., Jankowski R. Experimental and numerical study on pounding of structures in series. In: Advances in structural engineering: dynamics. India: Springer; 2015;2:1073-1089 (ISBN: 978-81-322-2192-0)

23. Crozet V, Politopoulos I, Chaudat T. Shake table tests of structures subject to pounding. Earthq Eng Struct Dyn. 2019;48(10):1156-73.

24. Naderpour H, Naji N, Burkacki D, Jankowski R. Seismic response of high-rise buildings equipped with base isolation and non-traditional tuned mass dampers. Appl Sci. 2019;9(6):1201.

25. Monteiro M. Energy dissipation systems for buildings. Fenix.tecnico.ulisboa.pt, Corpus ID: 53343249, 2011

26. Kasai K, Jeng V, Patel PC, Munshi JA, Maison BF. Seismic pounding effects-survey and analysis. Proceedings of the 10th world conference on earthquake engineering, vol 7. Madrid, Spain, 19-24, July 1992, pp. 3893-3898

27. Xu YL, He Q, Ko JM. Dynamic response of damper-connected adjacent buildings under earthquake excitation. Eng Struct. 1999;21:135-48.

28. Ni YQ, Ko JM, Ying ZG. Random seismic response analysis of adjacent buildings coupled with non-linear hysteretic dampers. J Sound Vib. 2001;246:403-17.

29. Westermo BD. The dynamics of interstructural connection to prevent pounding. Earthq Eng Struct Dyn. 1989;18:687-99.

30. Bhaskararao AV, Jangid RS. seismic response of adjacent buildings connected with dampers. 13th World conference on earthquake engineering. Canada: Vancouver, B.C.; 1-6 August 2004, Paper No. 3143

31. Uz ME, Hadi MNS. Dynamic analysis of adjacent buildings connected by fluid viscous dampers. Earthquake resistant engineering structures, WIT Transaction on The Built Environment, 2009

32. Jankowski R, Mahmoud S. Linking of adjacent three-storey buildings for mitigation of structural pounding during earthquakes. Bull Earthq Eng. 2016;14(11):3075-97.

33. Passoni C, Belleri A, Marini A, Riva P. Existing structures connected with dampers: state of the art and future developments. Second European conference on earthquake engineering and seismology, Istanbul, Aug 25-29 2014

34. Gattulli V, Lepidi M, Potenza F, Ceci AM. Nonlinear viscous dampers interconnecting adjacent structures for seismic retrofitting. Eighth European conference on structural dynamics 2011, Belgium

35. Elwardany H, Seleemah A, Jankowski R. Seismic pounding behavior of multi-story buildings in series considering the effect of infill panels. Eng Struct. 2017;144:139-50.

36. Specification for Structural Steel Buildings, ANSI/AISC 360-10 June 2010

37. ADINA R\&D, Inc. Automatic dynamic incremental nonlinear analysis. Reference Manual June 2010 
38. Bathe KJ, Chaudhary A. A solution method for planar and axisymmetric contact problems. Int J Number Method Eng. 1985;21:65-88.

39. Elwardany H, Seleemah A, Jankowski R, El-khoriby S. Influence of soil-structure interaction on seismic pounding between steel frame buildings considering the effect of infill panels. Bull Earthq Eng. 2019;17(11):6165-202.

40. Sołtysik B, Jankowski R. Non-linear strain rate analysis of earthquake-induced pounding between steel buildings. Int J Earth Sci Eng. 2013;6(3):429-33.

41. Eurocode 3 (EN1993-1-5) Design of steel structures-part 1-5: plated structural elements, EN 1993-1-5:2006, incorporating corrigendum April 2009, 2006
42. Seleemah A, Constantinou MC. Investigation of seismic response of buildings with linear and nonlinear fluid viscous dampers, Report No. NCEER-1997-0004, National Center for Earthquake Engineering Research, Buffalo, New York, USA

43. McVitty W, Taylor A. Structures with supplemental energy dissipation devices. FEMA P-1051, NEHRP recommended provisions: design examples, Chapter 16, pp. 1-42, July 2016

Publisher's Note Springer Nature remains neutral with regard to jurisdictional claims in published maps and institutional affiliations. 